\title{
Adenoma de paratireóide diagnosticado por punção aspirativa por agulha fina: relato de caso
}

\section{Parathyroid adenoma diagnosed by fine needle aspiration cytology: a case report}

Marciênio Oliveira de Medeiros'; Rosalina Jenner Rosas²; Vladimir Gomes de Oliveira ${ }^{3}$; Sebastião Horácio da Nóbrega Neto ${ }^{4}$; Lincoln Santos Souza ${ }^{5}$; Maria Roseneide dos Santos Torres ${ }^{6}$

Unitermos
Paratireóide
Hiperparatireoidismo primário
Punção aspirativa por
agulha fina

\section{resumo}

Os autores relatam o caso de uma paciente com hiperparatireoidismo primário causado por adenoma de paratireóide diagnosticado através de punção aspirativa por agulha fina (PAAF) no pré-operatório. A paratireóide aumentada foi visualizada pela ultra-sonografia (US) e submetida à PAAF, que foi compatível com adenoma de paratireóide. Realizou-se a remoção cirúrgica do adenoma e o histopatológico resultou concordante com a citologia. Este relato destaca a importância da localização e do diagnóstico citológico pré-operatório das lesões de paratireóide para proporcionar uma abordagem cirúrgica menos agressiva.

\section{abstract}

The authors report a patient's case with primary hyperparathyroidism caused by parathyroid adenoma that was diagnosed by fine needle aspiration cytology (FNAC) in the preoperative. The increased parathyroid was visualized by the ultrasonography and submitted to FNAC that was compatible with parathyroid adenoma. The surgical removal of adenoma was accomplished and the histopathologic was concordant with the cytology. This report detaches the importance of the location and preoperative cytological diagnosis of the parathyroid lesions in providing a less aggressive surgical approach.

\section{key words}

Parathyroid

Primary hyperparathyroidism

Fine needle aspiration

cytology

\section{Introdução}

Adenoma de paratireóide (AP) é a causa de hiperparatireoidismo primário (HPTP) em cerca de $80 \%$ dos casos. Punção aspirativa por agulha fina guiada por ultra-sonografia (PAAF-US) de paratireóides, e dosagem de paratormônio (PTH) intacto no aspirado, podem ser realizadas quando paratireóides são visualizadas pela ultra-sonografia (US), podendo assim determinar o diagnóstico citológico e a localização pré-operatória da paratireóide aumentada e, desse modo, contribuir para realização de uma cirurgia menos invasiva. O objetivo deste relato é descrever um caso de HPTP causado por AP diagnosticado através de punção aspirativa por agulha fina (PAAF).

1. Médico residente de Endocrinologia do Hospital Universitário Alcides Carneiro da Universidade Federal de Campina Grande (HUAC/UFCC).

2. Mestre em Medicina e Saúde da Universidade Federal da Bahia (UFBA); médica especialista em Patologia; professora de Patologia e Anatomia Patológica do curso de Medicina da Universidade Federal de Campina Grande (UFCC).

3. Médico especialista em Endocrinologia; professor de Endocrinologia do curso de Medicina da UFCG.

4. Médico especialista em ultra-sonografia.

5. Médico especialista em cirurgia de cabeça e pescoço

6. Mestre em Medicina e Saúde da UFBA; médica especialista em Endocrinologia; professora de Endocrinologia do curso de Medicina da UFCC.

Trabalho realizado na Unidade de Endocrinologia e Diabetes do HUAC-UFCG.

Apresentado na forma de pôster no EndoRecife 2004, realizado de 8 a 11 de julho de 2004, em Porto de Galinhas-PE. 


\section{Relato do caso}

Paciente do sexo feminino, 55 anos, com queixa de dores em membros inferiores há seis meses e histórico de retirada de cálculo urinário há dez anos. Ao exame clínico apresentava nódulo palpável no lobo direito da tireóide, pressão arterial de $180 \times 100 \mathrm{mmHg}$ e edema discreto de membros inferiores.

Exames complementares mostraram osteoporose de rádio, coluna lombar e fêmur pela densitometria óssea, calciúria e PTH elevados. A cintilografia de paratireóides foi compatível com provável AP superior esquerdo. Na ultrasonografia (US) da tireóide observou-se imagem sugestiva de paratireóide, que foi submetida à PAAF. O exame citológico (Figuras 1 e 2) mostrou processo epitelial proliferativo, sem atipias, compatível com neoplasia benigna da paratireóide. A paciente foi submetida à ressecção do AP e o histopatológico (Figuras 3 e 4) confirmou o diagnóstico de adenoma.

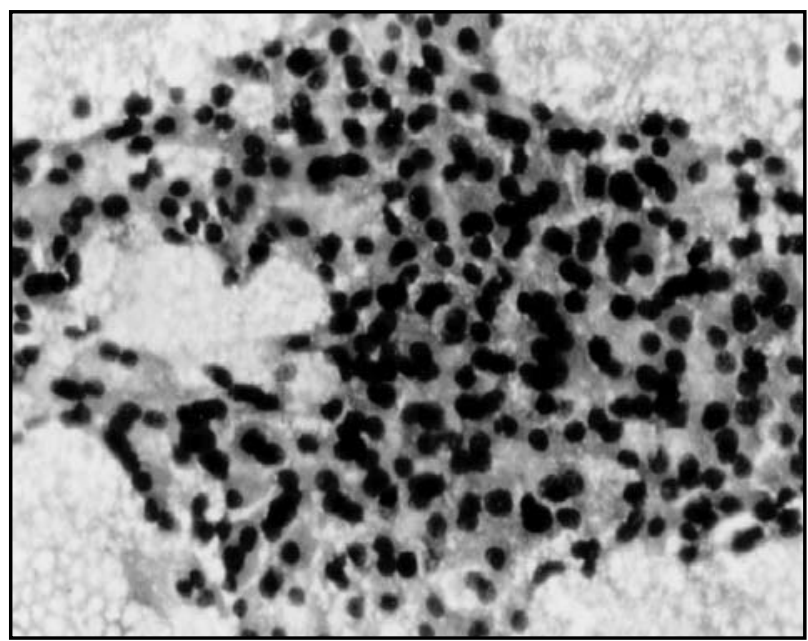

Figura 1 - PAAF de nódulo de paratireóde. Observe a ausência de colóide e a presença de pequenas células epiteliais de núcleos arredondados e citoplasmas discretamente granulares (giemsa, 10x)

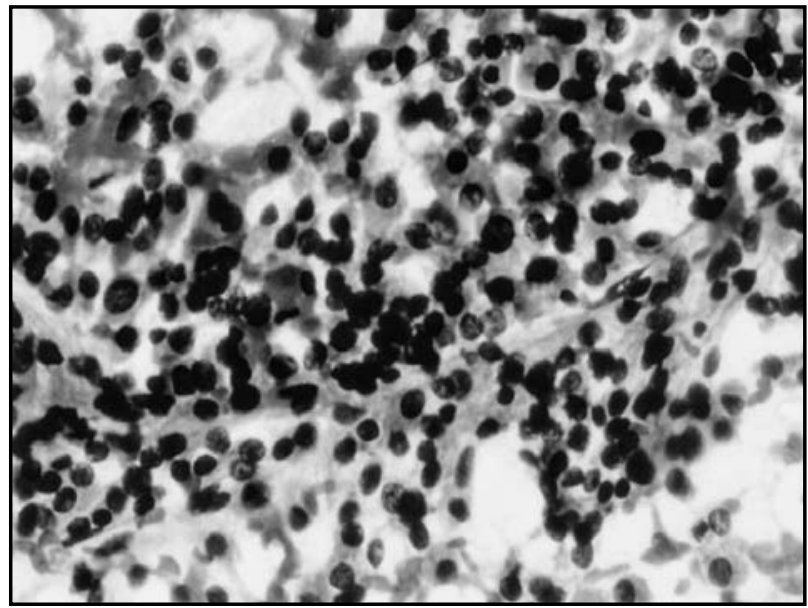

Figura 2 - PAAF de nódulo de paratireóde. Presença de agrupamento de pequenas células de núcleos arredondados. Nota-se ausência de colóide (papanicolau, 10x)

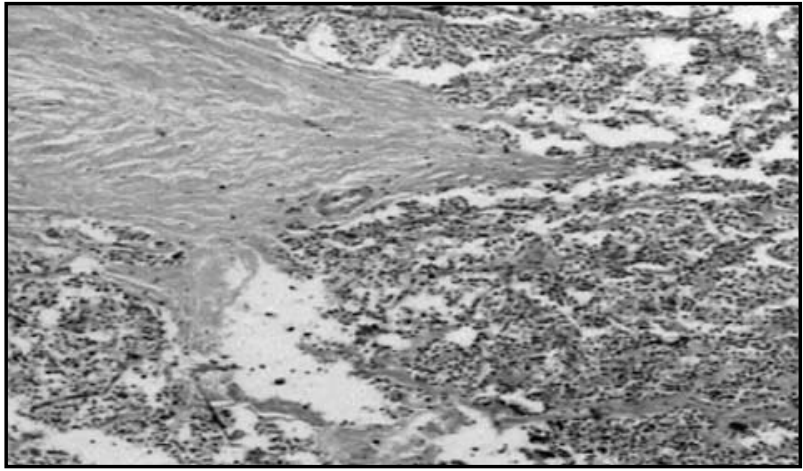

Figura 3 - Adenoma de paratireóide (HE 10x)

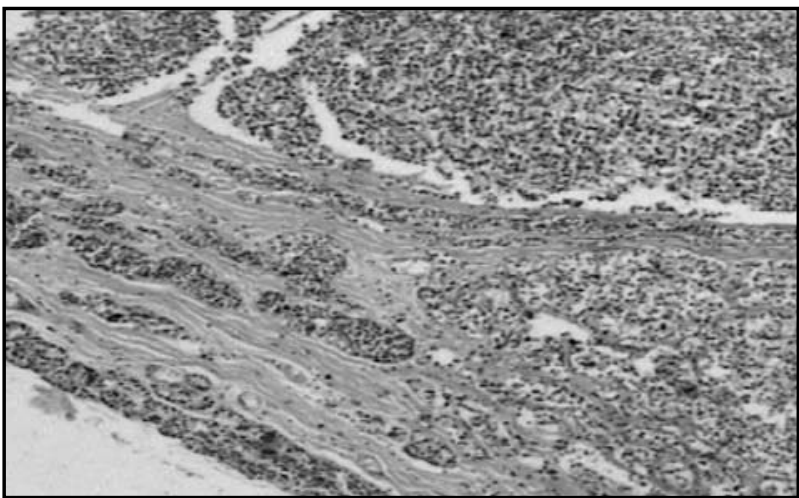

Figura 4 - Adenoma de paratireóide (HE 10x)

\section{Discussão}

A lesão mais comumente observada em pacientes com HPTP é o adenoma solitário de paratireóide, ocorrendo em $80 \%$ dos casos. Enquanto na maioria das vezes um adenoma único é observado, adenomas múltiplos têm sido relatados em apenas $2 \%$ a $4 \%$ dos $\operatorname{casos}^{(2,8)}$. Hiperplasia das paratireóides (HP), situação em que geralmente as quatro glândulas estão envolvidas, é observada em cerca de $15 \%$ dos pacientes com HPTP; sendo sua etiologia multifatorial, não apresenta aspectos clínicos que diferenciem doença única de doença múltipla ${ }^{(2)}$. Carcinomas de paratireóide são raros, correspondendo a menos de $1 \%$ a $2 \%$ dos casos de HPTP(9).

Adenomas de paratireóide são causados por mutações no DNA de células paratireoidianas. Essas mutações conferem uma vantagem proliferativa e/ou de sobrevivência para as células afetadas sobre suas vizinhas normais( ${ }^{(4)}$. Como conseqüência dessa vantagem, os descendentes de uma célula paratireoidiana - um clone de células - sofrem expansão clonal para produzir um adenoma.

A acurácia do diagnóstico pré-operatório de glândulas paratireóides aumentadas em pacientes com HPTP pode ser meIhorada pela combinação da US, PAAF-US e dosagem do PTH no aspirado ${ }^{(5)}$. Atualmente, a disponibilidade da US de alta resolução oferece a possibilidade da realização da PAAF-US, 
quando as paratireóides são visualizadas. Nódulos tireoidianos e linfonodos são os principais diagnósticos diferenciais de lesões de paratireóide na avaliação ultra-sonográfica ${ }^{(3)}$.

Existem algumas dificuldades no diagnóstico diferencial citológico entre adenoma, hiperplasia e carcinoma de paratireóide, mas material adequadamente colhido e cuidadosa avaliação dos aspectos citológicos ajudam nessa diferenciação(11).

Liu et al. realizaram trabalho com esse objetivo, tendo sido realizada PAAF intra-operatória de 14 casos, sendo nove AP e cinco HP. As lesões classificadas como adenoma mostraram abundante celularidade, com células epiteliais arranjadas em camadas, sincício ou padrão microfolicular. Individualmente, as células mostraram baixa relação núcleo-citoplasma, citoplasma microvacuolado e núcleo com uma cromatina finamente padronizada. Os casos de HP mostraram células ordenadas em camadas; um caso de HP mostrou alterações oncocíticas.

Oito, de nove casos de AP, continham grupos microfoliculares em adição a camadas e sincício de células, sendo esses microfolículos mais observados em AP que na HP. No geral, as células no AP foram mais pleomórficas, enquanto na hiperplasia foram mais uniformes ${ }^{(7)}$.

Tseng et al. revisaram 72 casos de HPTP submetidos a PAAF-US devido à suspeita de paratireóides aumentadas na US. Vinte casos eram de hiperplasia, 51 de adenoma e um de carcinoma, todos confirmados pelo histopatológico após a cirurgia. Lesões de paratireóide foram diagnosticadas citologicamente em 60 casos (83,3\%). A presença de colóide, macrófagos ou estrutura folicular nos esfregaços possibilitou que seis casos fossem erroneamente interpretados como tecido tireoidiano ${ }^{(11)}$.

Dificuldades citológicas em distinguir células tireoidianas de paratireoidianas têm sido relatadas por vários autores. Kini et al.$^{\left({ }^{(6)}\right.}$ e Abati et al. ${ }^{(1)}$ sugeriram a presença de estrutura folicular, material colóide e macrófagos como específicos para tecido tireoidiano. No entanto, Bondeson et al. ${ }^{(3)}$ mostraram que estrutura folicular, material colóide símile e macrófagos estavam presentes em 15\%, 21\% e 10\%, respectivamente, nos esfregaços citológicos de paratireóide, enquanto Tseng et al. ${ }^{(11)}$ identificaram material colóide símile e macrófagos em $24,2 \%$ e $9,1 \%$ dos esfregaços, respectivamente. Células paratireoidianas são, usualmente, menores que as células tireoidianas e mais pleomórficas. Células monomórficas em agrupamentos sólidos têm sido relatadas como características citológicas de lesões de paratireóide ${ }^{(6,10)}$.

Este relato mostrou que quando paratireóides aumentadas são visualizadas pela US, a PAAF-US de paratireóide pode ser realizada e proporcionar valiosas informações para o diagnóstico pré-operatório de lesões de paratireóide.

\section{Referências}

I. ABATI, A. et al. Ultrasound-guided fine-needle aspiration of parathyroid lesions:a morphological and immunocytochemical approach. Human pathology, v. 26, p. 338-43, 1995.

2. BILEZIKIAN, J.P. Primary hyperparathyroidism: diseases of bone and calcium metabolism (cap. 5). Disponível em: htpp: //www. endotext.com. Acesso em: jul. 2005.

3. BONDESON, L. et al. Cytopathological variables in parathyroid lesions: a study based on 1600 cases de hyperparathyroidism: diagnostic cytopathology. Hoboken, v. 16, p. 476-82, 1997.

4. BRINGHURST, R.F. et al. Hormones and disorders of mineral metabolism. In: LARSEN, P.R. et al. 10 ed. Philadelphia: Saunders, Williams Textbook of Endocrinology, 2002.

5. HALBAUER, M. Fine needle aspiration cytology in the preoperative diagnosis of ultrasonically enlarged parathyroid glands. Acto Cytologica, v. 35, n. 6, p. 728-35, 1991.
6. KINI, U. et al. Ultrasonically guided fine needle aspiration of the parathyroid: a report of two cases. Acta cytological, v. 37, p. 747-5।, 1993.

7. LIU, F. et al. Fine needle aspiration of parathyroid lesions. Acta Cytologica, v. 48, n. 2, p. 133-6, 2004

8. MARX, S.J. Hyperparathyroid and hypoparathyroid disorders. N Engl I of Med, v. 343, n. 25, p. 1863-75, 2000.

9. MIEDLICH, S. Update on genetic and clinical aspects of hyperparathyroidism primary. Clinical Endocrinology, v. 59, p. 539-54, 2003

10. RYSKA, A.; KEREKES, Z. Aspiration cytology of parathyroid adenoma: radioimmunoassay of parathormone in aspirate as a helpful diagnostic tool. Acta Cytologica, v. 42, p. 826-7, 1998.

I I.TSENG, F.Y. Ultrasound guided fine needle aspiration cytology of parathyroid lesions: a review of 72 cases. Acta Cytologica v. 46, n. 6, p. 1029-36, 2002
Endereço para correspondência

Marciênio Oliveira de Medeiros Rua Adelino Barbosa de Melo, 150 - Catolé CEP 58105-678 - Campina Grande-PB Tel.: (83) 3331-0035 e-mail: marcienioo@yahoo.com.br 